\title{
Fluid connections
}

\author{
Many of the impacts of climate change will be felt first through the presence - or absence - of water and access to \\ water resources. Water must be integrated into climate policy and adaptation planning to mitigate these impacts.
}

ust as rain seeps into the ground after a storm, water permeates every aspect of the Earth system, touching and connecting processes and impacts across the globe. This connecting flow of water also acts as a conduit for the tangible impacts of a changing climate. Climate change has diverse effects on the water cycle. Rising temperatures impact atmospheric moisture, circulation and precipitation patterns, which in turn changes the distribution of water across the globe, with some regions becoming wetter and experiencing flooding, and some drier and experiencing drought. Areas dependent on meltwater from snow and glaciers are also impacted by shifts in the timing and amount of flow, particularly as less water falls as snow.

Owing to its fundamental importance for life and deep interconnectedness with Earth's physical and ecological systems, water is likely to be the primary mechanism through which the impacts of climate change are felt. Understanding what these impacts will be and how to manage water resources fairly and sustainably in a changing climate is critical. In this issue of Nature Climate Change and associated focus, we feature pieces connecting climate and water resource impacts, as well as suggesting ways forward.

In addition to the direct effects of climate change on the water cycle, adaptation and mitigation strategies may also impact water demand. However, climate policy has historically focused on energy and land-use measures for reducing emissions, which often assume that water will be available and not limiting. Nonetheless, Nature-based Solutions such as planting forests or biofuels may require irrigation water, which can conflict with other water uses, like for agriculture or household use. Writing in a Comment in this issue, Fernando Miralles-Wilhelm argues for stronger inclusion of water

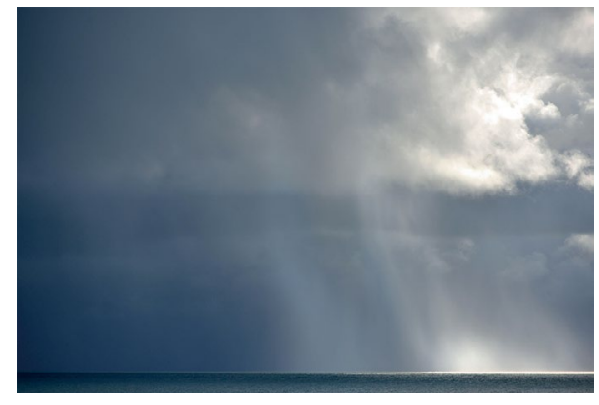

Credit: Peter Cripps / Alamy Stock Photo

constraints and water resource management in climate policy due to water's critical role in mitigation strategies and vulnerability to human activity. As an illustration of these points, Matteo Giuliani and co-authors show in their Article how global climate mitigation policies that are meant to regulate emissions from land use can unintentionally impact local water allocation. For their case study of the Zambezi Watercourse, these mitigation policies have the potential to create more risks for water resources than climate change itself.

The growing scarcity of water resources leads to concerns about rights and justice to ensure access for all stakeholders. Globally, around two billion people are not able to access water that is safe to drink (https://go. nature.com/3sbj0Pp) and current policies often disadvantage marginalized and vulnerable communities. In their Comment, Shilpi Srivastava and colleagues outline the importance of water for adaptation to climate change, as well as the need to address the underlying inequities in water access that impact peoples' ability to adapt. Similarly, in another Comment, Dylan Hedden-Nicely suggests reforms to the current water allocation system in the western United States, which has its roots in the exploitation of the west and fosters conflict and exclusion, particularly for Indigenous communities. A system more resilient to climate change would be founded in cooperation, include improved infrastructure and have more liberal and efficient laws governing management, with equity considered throughout.

Resource management, however, requires that the resource be present to manage. Water storage in very dry regions poses a challenge. In mountain areas where communities have long been reliant on streams carrying water melting from snow or glaciers, climate change is altering the timing and amount of meltwater. To control the predictability of water access, communities are turning to strategies for storing meltwater over longer time periods, such as through the construction of towers of ice known as ice stupas. A Feature in this issue describes the need for constructing such structures in the Himalayan region of Ladakh, as well as the associated engineering and practical challenges.

Water is critical for human survival and indeed for that of all life. Managing the limited freshwater resources available in the coming decades and ensuring equitable access will be challenging under changing precipitation patterns and increasing demands from different sectors. In a recent report (https://go.nature.com/3rVvLNw), the World Meteorological Organization warns of a pending water crisis, and urges improvements to management, monitoring and early warning systems related to water. The impacts of climate change are already being felt in many regions through water; concurrently with mitigation, water resource research and management should have a central role in ongoing adaptation and policy.

Published online: 8 February 2022 https://doi.org/10.1038/s41558-022-01295-8 